\title{
IOT CLOUD DATA LOGGER UNTUK SISTEM PENDETEKSI DINI BENCANA BANJIR PADA PEMUKIMAN PENDUDUK TERINTEGRASI MEDIA SOSIAL
}

\author{
Mokh. Sholihul Hadi ${ }^{1}$, Danang Alfian Tricahyo ${ }^{2}$, Dimas Kurniawan Sandy ${ }^{3}$, Fauzy Satrio \\ Wibowo ${ }^{4}$ \\ 1,2,3,4 Jurusan Teknik Elektro FT Universitas Negeri Malang \\ Email: mokh.sholihul.ft@um.ac.id
}

\begin{abstract}
Extreme weather changes in the world cause people to be aware of the occurrence of disasters that can happen at any time. As a tropical country Indonesia has two seasons of dry and rainy, due to extreme weather changes make the weather in Indonesia becomes erratic which causes the difference of the rainy season prolonged or vice versa. For today's frequent flood disasters, protection for houses is still very rare, especially to break the electric current when the floods occur. Therefore, a flood detection device is provided for home protection when a flood occurs. This flood protection system will work with automatic and realtime to know the height of the water surface at home. This water level monitoring system is performed by implementing Arduino nano-based ultrasonic sensors and esp 8266 modules for data logging at thingspeak.com, which will know the height of the water surface created at certain levels and when the sensor detects the hazard the appliance will disconnect electric current and send twitter status to let homeowners know about their home status.
\end{abstract}

Keywords: data logger, flood, arduino, esp 8266, social media

\begin{abstract}
ABSTRAK
Perubahan cuaca ekstrim di dunia menyebabkan masyarakat waspada akan terjadinya bencana yang sewaktu waktu dapat terjadi. Sebagai Negara tropis Indonesia memiliki dua buah musim yaitu panas dan hujan, karena perubahan cuaca ekstrim membuat cuaca di Indonesia menjadi tidak menentu yang menyebabkan perbedaan musim hujan berkepanjangan ataupun sebaliknya. Untuk bencana banjir yang dewasa ini sering terjadi, proteksi terhadap rumah masih sangat jarang dilakukan, terutama untuk memutus arus listrik saat banjir terjadi oleh karena itu dibuatlah alat deteksi banjir untuk proteksi rumah ketika banjir terjadi. Sistem proteksi akan banjir ini akan bekerja dengan otomatis dan realtime untuk mengetahui ketinggian permukaan air di rumah. Sistem pemantauan ketinggian permukaan air ini dilakukan dengan mengimplementasikan sensor ultrasonik berbasis Arduino nano dan modul esp 8266 untuk data logging di thingspeak.com, yang akan mengetahui ketinggian permukaan air yang dibuat pada level-level tertentu dan apabila sensor mendeteksi bahaya maka alat akan memutus arus listrik dan mengirim status twitter agar pemilik rumah tahu akan status rumahnya.
\end{abstract}

Kata kunci : data logger, banjir, arduino, esp 8266, media sosial

\section{PENDAHULUAN}

Inovasi teknologi yang berkembang sekarang ini sudah tidak dapat dielakkan, mau atau tidak seseorang pasti akan menerima perkembangan yang terjadi tersebut. Perkembangan inovasi-inovasi tersebut semakin memudahkan aktivitas kehidupan manusia dalam melakukan aktivitas sehari-harinya, bahkan perkembangan teknologi telah merambah segala aspek kehidupan, mulai dari kegiatan bersosial dalam masyarakat maupun dalam kegiatan yang dilakukan secara individu.

Inovasi teknologi yang diimplementasikan guna membantu kehidupan manusia disaat terjadi bencana alam seperti banjir yakni untuk sistem proteksi rumah saat banjir yang awal mulanya masih belum banyak yang menerapkan atau bahkan masih menunggu pihak PLN untuk memutuskan aliran listrik, dan juga deteksi percepatan bertambahnya air 
sehingga akan membantu masyarakat agar lebih siap saat air meluap dengan cepat, sehingga akan mempercepat pembacaan kondisi, dan pengambilan tindakan ketika ketinggian air telah berada pada level siaga banjir, level waspada hingga pada level bahaya. Camera digunakan untuk memantau keadaan rumah dengan dilengkapi gimbal yang dapat diatur posisinya menggunakan perangkat smartphone yang sudah dilengkapi sensor accelerometer..

Tujuan pembuatan tugas akhir ini adalah untuk mengimplementasikan dan mengadopsi sistem proteksi dini agar tidak terjadi korsletting listrik saat banjir dan membantu pemilik rumah membaca percepatan air sehingga akan bisa dibaca kondisinya apakah berpotensi banjir atau tidak untuk pemantauan realtime. Alat ini dikembangkan dengan sistem IoT (Internet of Thing) yang komunikasinya dilakukan secara wireless dengan media mikrokontroller ESP8266 dan sensor ultrasonik untuk mendeteksi ketinggian air.

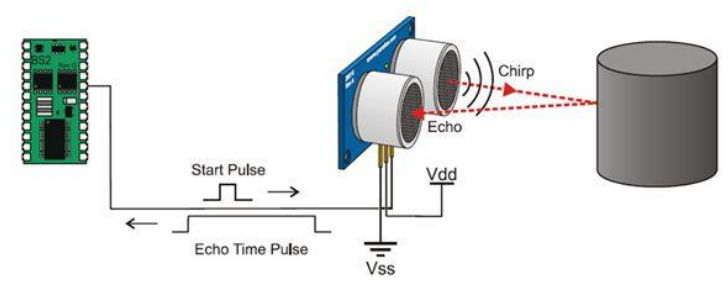

Gambar 1. Sistem deteksi jarak dengan sensor ultrasonic

\section{METODE PENELITIAN}

Sistem yang dibuat menggunakan (IOT) Sistem Internet Of Things yang telah dirancang dengan proses perencanaan, perancangan, implementasi, pengujian alat, pengambilan data dan analisis. Metode ini sering digunakan sebagai pengembangkan sistem di bidang teknik.

Alat yang dibuat memiliki fungsi untuk memantau dan memberikan peringatan terhadap kondisi ketinggian air dan percepatan air berbasis web. Sensor ultrasonic dikategorikan sebagai perangkat input, untuk memberikan nilai sensor. Sementara itu, monitoring pada web dikategorikan sebagai output dan digunakan untuk menampilkan nilai sensor secara real time. dan pengaturan sudut servo kamera berbasis web. Alat yang di buat secara rinci digambarkan sebagai berikut :

\section{Proses Perencanaan}

Pembuatan sistem otomatisasi deteksi banjir yang diterapkan pada daerah rawan banjir ini dilakukan setelah presentasi tugas akhir atau pertemuan ke 10 sampai 16 perkuliahan yang pelaksanaan kegiatan dilakukan di jam matakuliah system kendali jarak jauh dan kampus Universitas Negeri Malang.

\section{Proses Perancangan}

Pada proses ini yaitu alat dan bahan yang telah dibeli digunakan untuk membangun sistem mekanik dan komponen untuk pembuatan alat deteksi banjir untuk proteksi rumah ketika banjir serta pemutus aliran listrik.

\section{Blok Diagram}

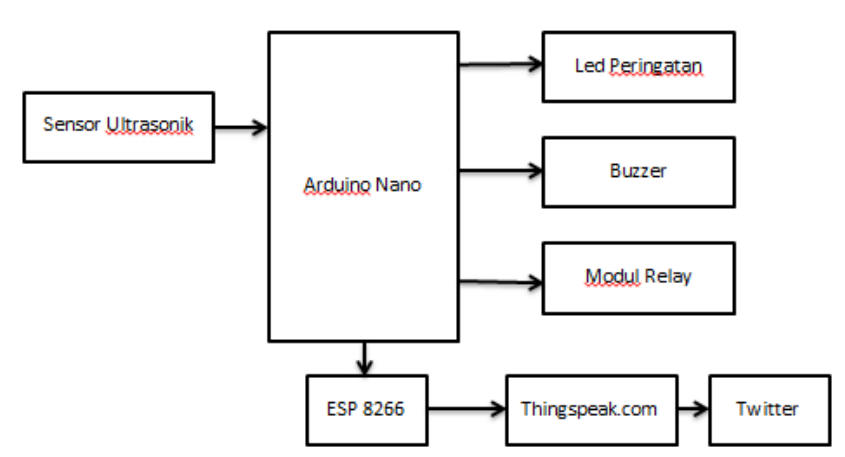

Gambar 2. Blok Diagram

Dari blok diagram terlihat sensor ultrasonic digunakan sebagai input Alat Deteksi. Untuk board kontrol menggunakan Arduino nano, hal ini karena pada nano memiliki 8 pin analog dan 12 pin digital yang dapat digunakan. Untuk actuator sendiri berupa modul relay sebagai pemutus aliran listrik dan buzzer serta 3 lampu indikator. Data yang diperoleh dari pembacaan sensor tersebut dikirimkan ke THINGSPEAK.COM melalui ESP8266. Data tersebut dapat dibaca oleh semua orang. 


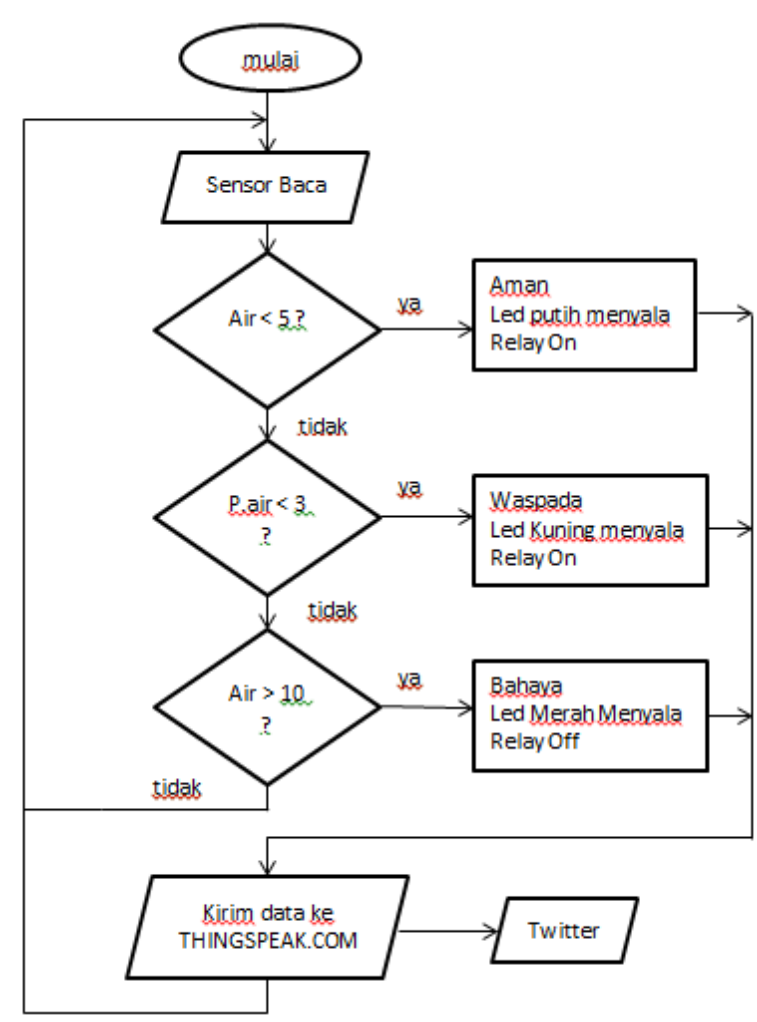

Gambar 3. Flowchart program utama

\section{Pengujian Alat}

Tahap kelima adalah pengujian alat diharapkan dengan adanya tahap ini fungsi kerja baik mekanik dan rangkaian yang telah dibuat sudah masuk dan sesuai dengan target yang diharapkan. Sehingga nantinya alat yang telah dibuat dapat bekerja secara maksimal.

\section{Pengambilan Data dan Analisis}

Mengambil data yang didapatkan pada saat pengujian, diharapkan pada tahap ini dapat ditemukan sebuah gagasan baru dalam mengurangi kesalahan pada tiap tahapan sebelumnya.

\section{Prinsip Kerja}

Prinsip kerja dari alat ini adalah, ketika sensor ultrasonic membaca keinggian air, ketika air dalam keadaan aman yaitu ketinggian air berkisar 0-5 cm, maka led putih menyala sebagai indikasi bahwa ketinggian air masih aman, kemudian apabila ketinggian air naik dengan percepatan lebih dari $3 \mathrm{~cm}$ dan ketinggian air melebihi $7 \mathrm{~cm}$ maka alat akan memberikan peringatan berupa bunyi buzzer dan juga lampu led kuning akan menyala berkedip tanda waspada banjir kemudian alat akan mengirim tweet ke pemilik rumah bahwa keadaan rumah sedang waspada banjir. Dan apabila ketinggian air melebihi $10 \mathrm{~cm}$ maka buzzer akan berbunyi dan led menyala serta mematikan aliran listrik rumah sebagai langkah proteksi bagi penghuni rumah sekaligus lingkungan sekitar, kemudian akan mengirim tweet agar pemilik tau bahwa sedang terjadi banjir dan listrik rumah dimatikan. Data pengukuran ketinggian dapat dibaca oleh pemilik rumah maupun masyarakat umum di website thingspeak.com dengan channel "Monitoring” dengan ID Channel : 268935.

Tabel 1. Sambungan pin perangkat keras

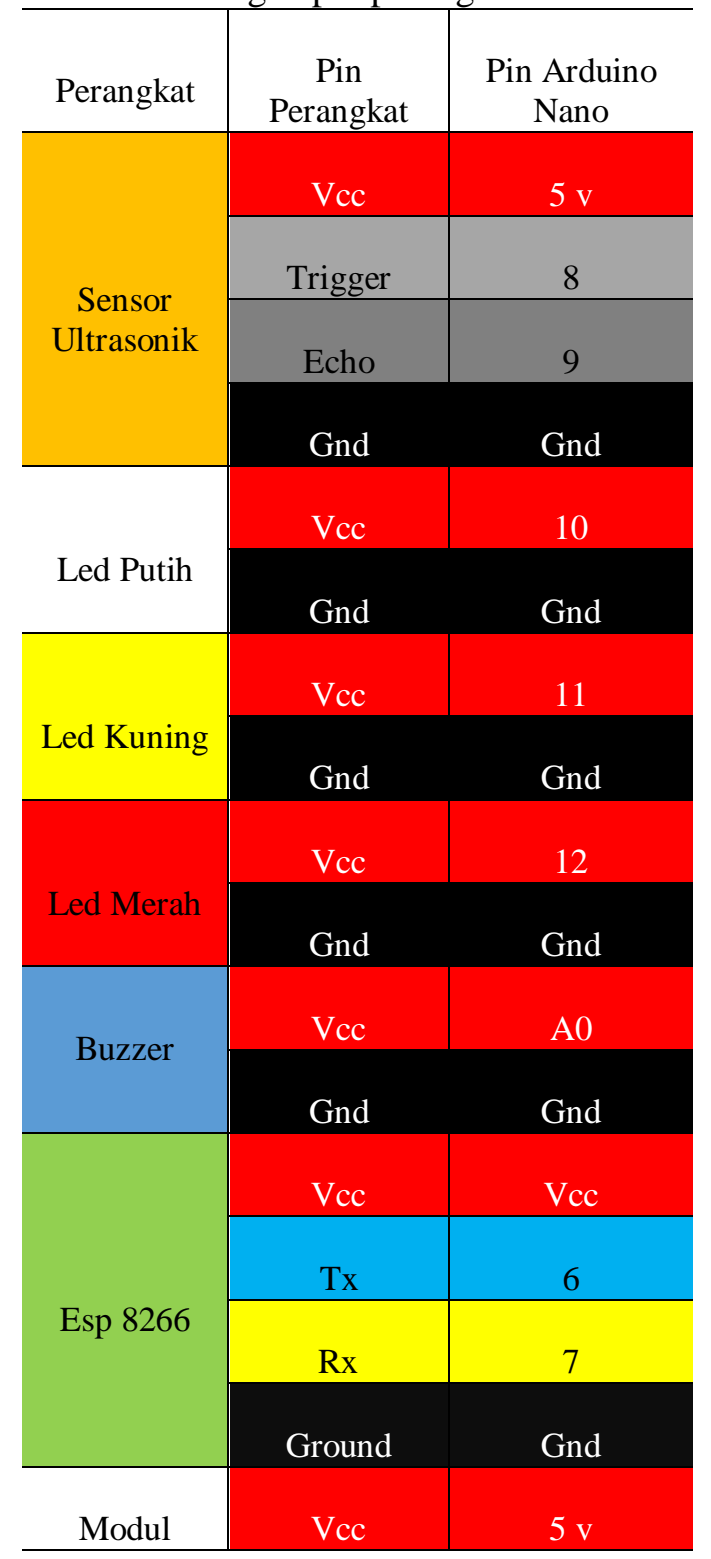




\begin{tabular}{c|c|c}
\hline \multirow{2}{*}{ Perangkat } & $\begin{array}{c}\text { Pin } \\
\text { Perangkat }\end{array}$ & $\begin{array}{c}\text { Pin Arduino } \\
\text { Nano }\end{array}$ \\
\hline Relay & Input 1 & 2 \\
\cline { 2 - 3 } & Input 2 & 3 \\
\cline { 2 - 3 } & Input 3 & 4 \\
\cline { 2 - 3 } & Input 4 & 5 \\
& Gnd & Gnd \\
\hline
\end{tabular}

\section{HASIL DAN PEMBAHASAN}

Pengujian dilakukan menggunakan media uji yang mampu menahan air sampai dengan kedalaman 1 meter. Tabel 2 menunjukkan kriteria ketinggian air dan status bahayanya. Pemberian kriteria hanya sebagai contoh, parameternya dapat disesuaikan dengan keadaan riil di masyarakat dengan mengganti angka bacaan sensor di program utama. Tabel 3 menunjukkan hasil pengujian dengan mempertimbangkan percepatan kenaikan kedalaman air.

Tabel 2. Kriteria ketinggian air dan statusnya pada sistem

\begin{tabular}{c|c|c}
\hline No. & kriteria & Kedalaman $(\mathbf{c m})$ \\
\hline 1. & Aman & $0-20$ \\
\hline $\mathbf{2 .}$ & Waspada & $21-45$ \\
\hline 3. & Bahaya & $>46$ \\
\hline
\end{tabular}

Tabel 3. Hasil Pengujian Level Air Pada Bak Mandi

\begin{tabular}{c|c|c}
\hline $\begin{array}{c}\text { Panjang } \\
\text { sesuai alat } \\
\text { ukur }\end{array}$ & $\begin{array}{c}\text { Hasil } \\
\text { pembacaan } \\
\text { sensor }\end{array}$ & Percepatan \\
\hline $5 \mathrm{~cm}$ & $4 \mathrm{~cm}$ & $0 \mathrm{~cm}$ \\
\hline $10 \mathrm{~cm}$ & $10 \mathrm{~cm}$ & $6 \mathrm{~cm}$ \\
\hline $20 \mathrm{~cm}$ & $21 \mathrm{~cm}$ & $11 \mathrm{~cm}$ \\
\hline $15 \mathrm{~cm}$ & $15 \mathrm{~cm}$ & $-5 \mathrm{~cm}$ \\
\hline $40 \mathrm{~cm}$ & $39 \mathrm{~cm}$ & $24 \mathrm{~cm}$ \\
\hline $50 \mathrm{~cm}$ & $51 \mathrm{~cm}$ & $11 \mathrm{~cm}$ \\
\hline $35 \mathrm{~cm}$ & $34 \mathrm{~cm}$ & $-16 \mathrm{~cm}$ \\
\hline $70 \mathrm{~cm}$ & $70 \mathrm{~cm}$ & $35 \mathrm{~cm}$ \\
\hline
\end{tabular}

Dari 8 kali pengujian, sensor membaca data sesuai ketinggian sebenarnya dengan beberapa kali error pembacaan $1 \mathrm{~cm}$. dengan kata lain error pembacaan masih dalam tingkatan kecil sehingga akurasi pembacaan bagus. Percepatan diperoleh dari data sekarang dikurangi data sebelumnya.

Pengujian keseluruhan dilakukan dengan mengintegrasikan dengan IOT cloud dan media sosial twitter, seperti ditunjukkan dalam Tabel 4. Hasil pengujian bekerja dengan baik dengan kinerja alat yang sesuai dengan perencanaan.

Tabel 4. Hasil pengujian keseluruhan sistem data logger alat

\begin{tabular}{|c|c|c|c|c|}
\hline Waktu & Jarak & Twitter & Led & Buzzer \\
\hline $16: 21$ & $5 \mathrm{~cm}$ & - & putih & off \\
\hline $16: 22$ & $10 \mathrm{~cm}$ & Status & merah & on \\
\hline $16: 23$ & $7 \mathrm{~cm}$ & - & kuning & on \\
\hline $16: 24$ & $5 \mathrm{~cm}$ & - & Putih & off \\
\hline $16: 25$ & $15 \mathrm{~cm}$ & Status & Merah & on \\
\hline $16: 26$ & $20 \mathrm{~cm}$ & & Merah & on \\
\hline $16: 27$ & $5 \mathrm{~cm}$ & - & Putih & off \\
\hline \multicolumn{5}{|c|}{ Tweets \& replies } \\
\hline \multicolumn{5}{|c|}{$\begin{array}{l}\text { Danang Alvian @AlvianDanang } 58 \text { · } 10 \mathrm{~h} \\
\text { BANIR SEDANG TERJADI. } \\
\text { UNTUK KEAMANAN, LISTRIK RUMAH ANDA DIMATIKAN SISTEM... TERIMAKASIH } \\
\text { @ Translate from Indonesian }\end{array}$} \\
\hline
\end{tabular}

Gambar 4. Tampilan status bencana pada twitter

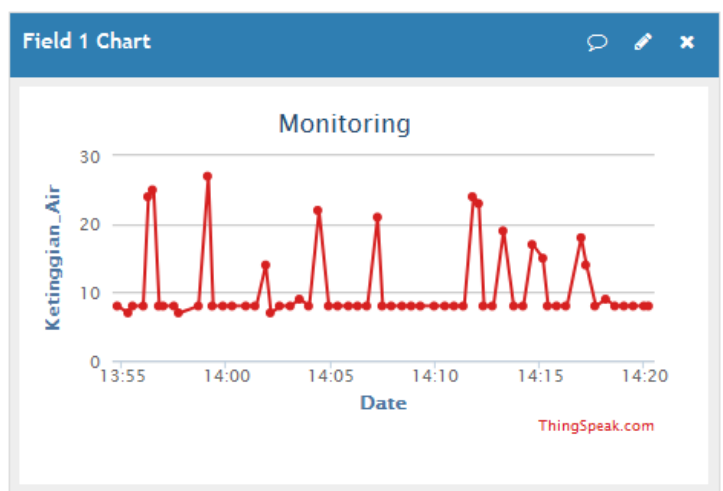

Gambar 5. Tampilan grafik Monitoring Ketinggian Air pada thinkspeak 


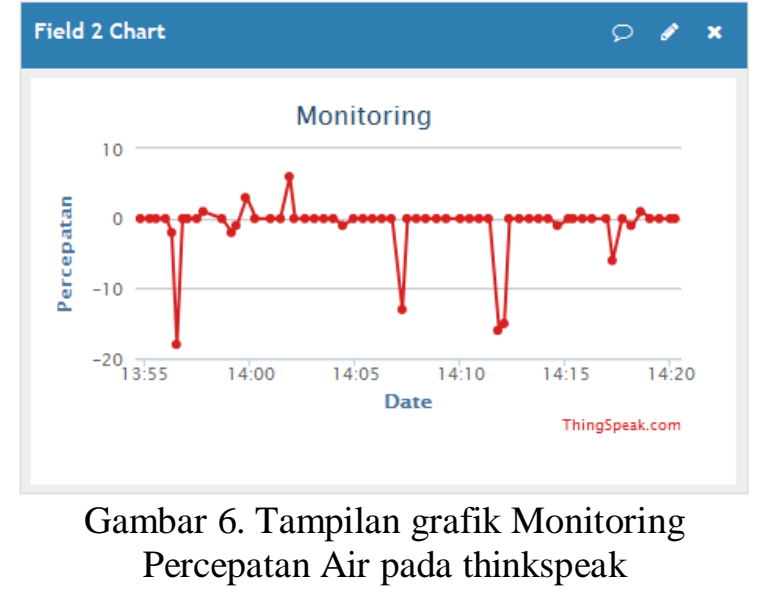

\section{SIMPULAN}

Hasil pengujian menunjukkan bahwa sistem telah bekerja dengan baik. Alat mampu mendeteksi perubahan ketinggian air dan mengirimkan status bahayanya terintegrasi melalui saluran media social twitter. Eror pembacaan jarak sejumlah $\pm 1 \mathrm{~cm}$ merupakan angka yang bisa ditolelir dalam implementasi riil sistem di kondisi sebenarnya. Tampilan grafik pada IOT cloud data logger memudahkan analis untuk memantau percepatan dan mengkalkulasi potensi bahaya, untuk kemudian dihubungkan pada instansi penanggulangan bencana.

\section{DAFTAR RUJUKAN}

Basha, E., Rus, D. 2007. Design of early warning flood detection systems for developing countries. IEEE Trans. 612 6175.

Eko Waluyo Jati, Muhammad Arrofiq. 2013. "Sistem Pemantau Ketinggian Air Sungai Dengan Tampilan Pada Situs Jejaring Sosial Twitter Sebagai Peringatan Dini Terhadap Banjir. Universitas Gadjah Mada, Yogyakarta.

Guochao, W., Changzan, G., Jennifer, R., Takao, I., Changzhi, L. 2013. Highly accurate noncontact water level monitoring using continuous-wave doppler radar. IEEE

Parallax. 2006. PING ${ }^{\mathrm{TM}}$ Ultrasonic Distance Sensor (\#28015) 1 no. 3 1-13. Parallax. California.

Raj B, Kalgaonkar K, Harrison C, Dietz P. 2012. "Ultrasonic Doppler Sensing in HCI". IEEE. doi: 0.1109/MPRV.2012.17

Taufiqurrahman, Basuki A, Albana Y. 2013. "Perancangan Sistem Telemetri Untuk Pengukuran Level Air Berbasis Ultrasonic”. Proceeding Conference on Smart-Green Technology in Electrical and Information Systems [internet]. Bali (ID). hlm 125 - 130 . 